\title{
Saberes docentes e concepções do ensino religioso
}

\author{
Sérgio Junqueira* \\ Edile Maria Fracaro Rodrigues**
}

\section{Resumo}

Este artigo é parte de uma pesquisa qualitativa sobre o impacto da formação para o efetivo trabalho da docência e sua relação com a concepção de Ensino Religioso Escolar no cenário brasileiro e busca compreender essa relação utilizando como referencial os saberes docentes, de Maurice Tardif (2002, 2005). O Ensino Religioso Escolar assumiu diferentes características legais e pedagógicas na história brasileira. Nessa reflexão, dois elementos são significativos para compreender o Ensino Religioso Escolar: as propostas para a formação docente e as concepções organizadas ao longo da história da educação brasileira. No Brasil, a formação docente para o Ensino Religioso Escolar pressupõe a compreensão de que o saber religioso não assume a proposta da fé. O componente curricular pode ser estruturado como um dos marcos de leitura e interpretação da realidade, essenciais a participação do cidadão na sociedade de forma autônoma. Assume-se, assim, a perspectiva do Ensino Religioso a partir da escola, como orientação de um processo articulador no dia a dia da sala de aula, desafiando o (re) olhar sobre o processo de ensino-aprendizagem.

Palavras-chave: Ensino Religioso Escolar; Estudo de Religião; Formação de Professores no Brasil; Saberes Docentes.

\section{Teacher knowledge and conceptions of religious education}

\footnotetext{
Abstract

This article is part of a qualitative research on the impact of training for the effective work of teaching and its relationship with the conception of religious teaching in the Brazilian scenario and seeks to understand this relationship using as reference the teaching knowledge, by Maurice Tardif (2002, 2005). School Religious Education has

* Doutor e Mestre em Ciência da Educação; Licenciado em Pedagogia; Bacharel em Ciências Religiosas, Diretor do Instituto de Pesquisa e Formação Educação e Religião; Foi porfessor Titular da PUCPR. Email: srjunq@gmail.com

** Doutora em Teologia, Mestra em Educação; Licenciada e Educação. Email: edilefracaro@gmail.com
} 
assumed different legal and pedagogical characteristics in Brazilian history. In this reflection, two elements are significant for understanding School Religious Education: the proposals for teacher education and the conceptions organized throughout the history of Brazilian education. In Brazil, teacher education for religious school presupposes the understanding that religious knowledge does not assume the proposal of faith. The curriculum component can be structured as one of the milestones of reading and interpretation of reality, essential citizen participation in society in an autonomous way. Thus, we assume the perspective of Religious Education from school, as guidance of an articulating process in the classroom, challenging the (re) look at the teachinglearning process.

Keywords: School Religious Education; Study of religion; Teacher Training in Brazil; Teaching knowledge

\section{Saberes docentes y concepciones de la enseñanza religiosa}

\section{Resumen}

Este artículo es parte de una pesquisa cualitativa sobre el impacto de la formación en el trabajo efectivo de la docencia y su relación con la concepción de Enseñanza Religiosa Escolar en el escenario brasileño e intenta comprender esa relación utilizando como referencial los saberes docentes, de Maurice Tardif (2002, 2005). La Enseñanza Religiosa Escolar asumió diferentes características legales y pedagógicas en la historia brasileña. En esta reflexión, dos elementos son significativos para comprender la Enseñanza Religiosa Escolar de la educación brasileña. En Brasil, la formación docente para la Enseñanza Religiosa Escolar presupone la comprensión de que el saber religioso no asume la propuesta de la fe. El componente curricular puede ser estructurado como uno de los marcos de lectura e interpretación de la realidad, esenciales para la participación del ciudadano en la sociedad de forma autónoma. Se asume, así, la perspectiva de la Enseñanza Religiosa a partir de la escuela, como orientación de un proceso articulador del día a día de la sala de clase, desafiando la (re) visión del proceso de enseñanzaaprendizaje.

Palabras clave: Enseñanza Religiosa Escolar; Estudio de Religión Formación de Profesores en Brasil; Saberes Docentes.

Este artigo, resultado de pesquisa qualitativa bibliográfica sobre o Ensino Religioso no Brasil é parte de um estudo sobre o Ensino Religioso no continente americano. O presente estudo parte do cenário brasileiro e progressivamente busca relação com outras regiões como América Latina e Europa. Visa estabelecer as referências sobre a concepção de Ensino Religioso Escolar e sua respectiva formação docente. É o início de diálogo no cenário latino-americano.

Em países da região Latino-Americana, verifica-se que o perfil do Ensino Religioso se dá a partir da Igreja Católica. É o caso do Ensino Religioso na Colômbia, que a partir das normas legais deste país, é pluriétnico 
e emana várias formas de representações culturais e religiosos expressas em tradições pré-colombianas (LEME, 2018, p. 29), estilos de vida indígenas, ascendência africana e até mesmo influência protestante. Entretanto, na Colômbia, o trabalho referente a esta disciplina está orientado para o ensino católico junto às escolas de educação básica (VIDES, 2016, pp. 86-88).

Historicamente, o Ensino Religioso é um componente curricular presente na legislação de diferentes países, caracterizado mais pelo uso de manuais de comunidades cristãs na escola. Tal constituição se deu em decorrência de acordos com instituições religiosas em diversos países que, por meio desta disciplina, procuram manter uma forma de intervenção no espaço público escolar.

Para Pinto (2012, p. 11), "Espanha, a Inglaterra e a França, equacionaram profundamente a relação entre as instituições do Estado e as religiões, tendo como ponto de chegada a relação entre estas e a instituição escolar”. Na França, desde meados dos anos noventa, o declínio e o desaparecimento de uma cultura religiosa nas camadas mais jovens da população tem sido uma grande preocupação. No Colóquio Formeetsens, realizado na École du Louvre em 1996, "se equacionou o modo de o Estado dar resposta a esta questão que, na prática, se deve pensar, pelo menos, no campo das heranças patrimoniais e culturais" (PINTO, 2012, p 11).

A partir do exposto por Pinto (2012), vê-se os conhecimentos como "marcas da humanidade", e aqui inclui-se o conhecimento religioso e os aspectos da diversidade cultural e religiosa, marca importante na constituição do povo brasileiro.

Historicamente diversificado e plural, diferentes manifestações no campo religioso ajudaram a construir a identidade brasileira. Assim, o Ensino Religioso Escolar assume o papel de favorecer a compreensão dessa diversidade cultural e religiosa brasileira. E a construção dessa referência ocorre a partir da Ciência da Religião.

O Ensino Religioso Escolar assumiu diferentes características legais e pedagógicas na história brasileira. E sua trajetória passou por um lento processo de alteração em consequência do desenvolvimento do Estado e, portanto, das opções políticas, e de sua compreensão enquanto componente curricular.

A atual proposta de educação básica brasileira visa contribuir para o desenvolvimento integral de crianças e adolescentes e formação para a cidadania. O Ensino Religioso Escolar é proposto como parte integrante 


\section{Sérgio Junqueira}

Edile Maria Fracaro Rodrigues

da formação básica do cidadão disposto pela Lei de Diretrizes e Base da Educação Nacional 9394 (BRASIL, 1996).

Cabe ressaltar que os valores da fé continuam sendo prerrogativas da Família e da Igreja. À escola cabe proporcionar um espaço de discussão e reflexão sobre as questões fundamentais da existência do ser humano, longe de quaisquer formas de proselitismo.

Nessa reflexão, dois elementos são significativos para compreender o Ensino Religioso Escolar: as propostas para a formação docente e as concepções organizadas ao longo da história da educação brasileira.

A necessidade de pesquisa sobre esses elementos de compreensão do Ensino Religioso Escolar levou à criação do Grupo de Pesquisa Educação e Religião (GPER). Registrado em 2000, em Curitiba (Paraná). O GPER, que conta com pesquisadores em todas as regiões do país, vem mapeando a história do Ensino Religioso no Brasil e buscando a construção de uma identidade pedagógica para esse componente curricular.

Em 2001 o GPER organizou o Programa Concepções e Recursos do Ensino Religioso. Esse programa tinha como objetivo analisar o contínuo processo de construção da identidade do Ensino Religioso como componente curricular no cenário da educação brasileira, bem como diferentes recursos e estratégias de ensino que colaborassem com a formação docente.

A partir desse programa foi desenvolvido o Projeto Concepção e Produção do Ensino Religioso Escolar que visa especificamente o estudo da formação docente. No cenário brasileiro, a formação de professores do Ensino Religioso está vinculada diretamente à concepção de Ensino Religioso, que foi sendo estabelecida ao longo da história da disciplina.

Os primeiros núcleos de pesquisa sobre o Ensino Religioso Escolar foram sobre a história, os eixos e as legislações no cenário brasileiro em instituições públicas e provadas.

De 2000 a 2010 foram pesquisados os Eixos do Ensino Religioso Escolar e a História Contemporânea do Ensino Religioso Escolar.

De 2007 a 2012 a pesquisa se concentrou na identificação e coleta de fontes e mapeamento de diferentes fontes Publicação do Relatório. O resultado da pesquisa gerou o "Mapa da Produção Científica (2012 Disponibilização do Banco de dados do GPER (db.gper.com.br).

De 2013 a 2017 ampliou-se a identificação da situação do Ensino Religioso nas 27 Unidades Federativas do Brasil (Projeto Interinstitucional) por meio de atualização da coleta de produção científica. 
Até 2015, o mapa da produção científica do ER, identificou 1575 documentos analisados (237 dissertações de mestrado, 38 teses de doutorado, 780 artigos em eventos, 362 artigos em periódicos; 139 livros teóricos e 25 capítulos em livros de temática diversa), conforme Junqueira et al (2017, p. 315).

A atual etapa, em parceria com o Programa de Pós-Graduação em Ciência da Religião da Universidade Estadual do Pará (UEPA) e o Grupo de Pesquisa Educação e Religião (GPER), busca compreender esta relação utilizando como referencial os saberes docentes, de Maurice Tardif (2002, 2005).

\section{Saberes docentes}

Visando a qualificação dos professores, verifica-se a importância de compreender que cada indivíduo é gestado em um contexto cultural que interferirá na leitura de mundo, nas informações e no estudo sistemático de sua própria formação, pois, efetivamente cada um é constituído por meio de redes discursivas oriundas da cultura sobre gênero, biologia e corpo.

Da mesma forma, ser professor se institui nos discursos acadêmicos, sociais, escolares, históricos. O ser o que quer que seja se constitui na cultura. A escola tem sua cultura específica de produção de saberes e dos membros que participam de sua estrutura institucional. Os professores são constituídos pelo título e colados a ele, onde há uma carga de significados, que são deste mundo moderno e que não "podem" ser pensados diferentemente. Com a palavra e o significado cultural, que ela carrega, se produz o professor em todas as suas variantes: tradicional, outsider, criativo, sensível, amigo.

É claro que esta produção não é exclusiva da cultura escolar, ela se faz intra e extramuros da escola, mas é na escola que o professor tem o espaço onde exercita o seu papel determinado.

A cultura escolar é classificadora e produtora de identidades, tanto quanto os outros espaços sociais de convivência. No entanto, a diferença de poder entre esses espaços pode estar na autoridade conferida socialmente à escola, onde a classificação pode ser oficializada e determinante (SILVA, 2006, p. 203).

O professor é antes de tudo alguém que sabe alguma coisa e cuja função é transmitir esse saber, embora, não se reduza a isso, e esse conhecer não seja uma questão banal como se pode pensar inicialmente.

O saber do professor é um saber plural, já que é alguém que deve conhecer sua matéria, sua disciplina e seu programa; e que deve possuir certos conhecimentos das Ciências da Educação e da Pedagogia, sem deixar 


\section{Sérgio Junqueira}

Edile Maria Fracaro Rodrigues

de desenvolver um saber prático fundado em sua experiência cotidiana com estudantes.

Os saberes da formação são exteriores aos professores. Esses são constituídos em instâncias às que os professores não têm acesso como produtores, portanto são conhecimentos impostos por seus produtores oficiais como os cientistas, os pedagogos, os governos, etc. Os professores são desautorizados, neste sistema, para selecionar os saberes, agindo como meros transmissores ou técnicos instrumentados pelas instituições formativas para perpetuarem alguns conhecimentos selecionados na cultura acadêmica.

$\mathrm{Na}$ sala de aula, onde o currículo de fato se faz, o professor utiliza sua cota de liberdade enfatizando alguns tópicos em detrimento de outros. Esta prática está essencialmente vinculada aos saberes da experiência e, segundo os professores, pouco tem relação com os saberes de formação ou com referências teóricas. Os saberes de formação, quando frente aos saberes da experiência, são questionados. Os professores, de posse dos saberes da prática, refletem sobre seus cursos de formação, como podemos ver na fala de alguns professores presente nos cursos de licenciatura.

Cada sociedade, cada cultura gera suas próprias formas de aprendizagem, ou sua cultura de aprendizagem. Desta forma, a aprendizagem da cultura acaba por conduzir a uma cultura de aprendizagem determinada.

As atividades de aprendizagem devem ser entendidas no contexto das demandas sociais que as geram, pois não é só em distintas culturas que se aprendem coisas diferentes, é que as formas e os processos de aprendizagem culturalmente relevantes variam.

Neste sentido, não podemos deixar de considerar que o ensino como uma prática social, que está imbricado nas diferentes formas de trabalho dos professores, com suas diferentes concepções de mundo, de sociedade, de educação e de escola, o que torna a tarefa ainda mais complexa, é uma prática social complexa, realizado por seres humanos entre seres humanos; é transformado pela ação e relação entre os sujeitos (professores e estudantes) situados em diferentes contextos, por exemplo: institucionais, culturais, espaciais, temporais e sociais.

Da parte dos professores em formação, a partir dos saberes aprendidos durante a formação inicial (saberes das disciplinas e saberes da formação profissional), espera-se que eles sejam capazes de no dia a dia da sala de aula reconstruir e reformular esses saberes, assim como construir outros, que serão necessários para as suas atividades como docentes na escola básica. 
Para isso é preciso que os professores formadores dominem o conjunto de saberes que devem colocar ao alcance dos futuros professores (FOSSAT'TI; SARMENTO; GUTHS, 2012, pp. 72-73).

Os professores possuem saberes específicos, que são mobilizados, utilizados e produzidos por eles no âmbito de suas tarefas cotidianas. São os professores que ocupam na escola a posição fundamental, pois são os principais atores e mediadores da cultura e dos saberes escolares. Existe história, emoção, afetividade, crença e cultura na transmissão do saber. Compreendemos então, que existe o inconsciente nessa transmissão. Essa questão propõe que se pare de considerar o professor como um técnico que aplica conhecimentos produzidos por outros, ou como um agente social que aplica o conhecimento determinado por forças ou mecanismos sociológicos. O professor produz novos saberes sobre saberes anteriormente adquiridos. Ensinar significa aprender a ensinar, a dominar progressivamente os saberes docentes ao longo do tempo.

Existe uma importância das experiências familiares e escolares anteriores à formação inicial do docente. Essas experiências são muito significativas, pois o professor foi aluno por muitos anos e nesse período adquiriu crenças, representações e certezas sobre o que é ser professor. Portanto, acontece um novo equilíbrio entre o que se produz e o que se faz, pois, muitas vezes, os conhecimentos são produzidos em redomas sem conexões com as práticas profissionais. Levar em consideração o saber docente cotidiano permite renovar concepções a respeito da formação do professor, bem como de sua identidade e contribuição profissional (FONTANA, 2015, pp. 104).

Compreendendo que o saber profissional dos professores é um amálgama de diferentes saberes, provenientes de fontes diversas, que são construídos, relacionados e mobilizados pelos professores, de acordo com as exigências de sua atividade profissional (SERRES, 2008, p. 429).

Sendo que os saberes disciplinares são aqueles saberes produzidos pelos pesquisadores e cientistas envolvidos com atividades de pesquisa nas diferentes áreas de conhecimento. Logo, apesar de não se encontrarem envolvidos no processo de produção dos saberes disciplinares, os professores têm como uma das suas funções principais extrair desses saberes aquilo que é importante ser ensinado. Assim como o saber experiencial dos professores é bem específico, no sentido de trazer novos elementos para a reflexão a respeito da importância da experiência prática na constituição dos professores. 


\section{Sérgio Junqueira}

Edile Maria Fracaro Rodrigues

Quer se trate de um momento único ou repetido infinitas vezes, a experiência do professor não deixa de ser uma coisa pessoal e, acima de tudo, privada. Embora o professor viva muitas experiências das quais tira grande proveito, tais experiências, infelizmente, permanecem confinadas ao segredo da sala de aula. Ele realiza julgamentos privados, elaborando ao longo do tempo uma espécie de jurisprudência composta de truques, de estratagemas e de maneiras de fazer que, apesar de testadas, permanecem em segredo (TARDIF e LESSARD, 2005, pp. 51-52).

Ou seja, o julgamento e as razões nas quais o professor se baseia nunca são conhecidos, nem testados publicamente. Enquanto os seus saberes experienciais são resultado de um processo de construção individual, ao mesmo tempo são também compartilhados e legitimados por meio de processos de socialização profissional.

Nesse sentido, a interação entre os professores desencadearia um processo de valorização e de reconhecimento desses saberes, como saberes de uma classe e não de um profissional em específico. Entretanto, esse processo não parece suficiente, no sentido de garantir que a sociedade reconheça que os professores possuem um saber que é característico (BLOCK; RAUSCH, 2014, pp. 252-253). É preciso que os saberes experienciais dos professores sejam verificados por meio de métodos científicos e, então, divulgados e reconhecidos como o saber profissional dos professores.

Os saberes da ação pedagógica seriam então os saberes experienciais dos professores a partir do momento em que se tornam públicos e são validados por meio de pesquisas realizadas tendo como cenário empírico a sala de aula. Desta forma, a respeito da necessidade de que se validem e se tornem públicos os saberes experienciais dos professores é, nesse sentido, o que possibilitaria a construção de uma teoria da pedagogia.

A grande questão em relação aos saberes da ação pedagógica é que são saberes que têm origem na relação entre todos os saberes que o professor utiliza na atividade de ensinar. E ficam guardados, escondidos e condenados a ser uma espécie de segredo dividido só entre aqueles que compartilham da mesma atividade. O processo que resulta no escamoteamento dos conhecimentos que os professores produzem, a partir de sua ação, é facilitado, também, pela própria organização da escola. Ao analisar a escola, como lugar de organização do trabalho docente, destaca que quanto mais complexa a escola foi se tornando, ao longo do tempo, mais os professores se tornaram isolados e confinados ao espaço de suas salas de aula. 
O saber dos professores do Ensino Religioso Escolar é produzido e ressignificado por meio da prática, seja estudado, divulgado e validado pelos pesquisadores das Ciências da Educação e também pelos próprios professores.

Não poderá haver profissionalização do ensino enquanto esse tipo de saber não for mais explicitado, visto que os saberes da ação pedagógica constituem um dos fundamentos da identidade profissional do professor. De fato, na ausência de um saber da ação pedagógica válido, o professor, para fundamentar seus gestos, continuará recorrendo à experiência, à tradição, ao bom senso. Em suma, continuará usando saberes que não somente podem comportar limitações importantes, mas também não o distingue em nada, ou em quase nada, do cidadão comum.

O discurso pedagógico, por ser prescritivo e impor modelo de atuação, traduz e simplifica a teoria. Dessa forma, a educação padece de mal-estar estrutural, em relação ao conhecimento científico, cujo acesso irrestrito é negado aos educadores. A área expressa dificuldades em relacionar a teoria (de cunho interpretativo) à prática (de cunho prescritivo), ao não preservar a natureza distinta dessas operações. Essa cisão se expressa, por exemplo, na dissociação existente entre o bacharelado e a licenciatura, limite preestabelecido ao conhecimento e à capacidade de conhecer (TARDIF, LESSARD, 2005, pp. 49-50).

Outro aspecto relacionado à formação dos professores, diz respeito às metodologias de ensino, ou seja, à necessidade de se aprender como ensinar. No processo histórico da constituição da função de professor na modernidade, o ensino, ao se destacar como ocupação secundária de religiosos de algumas congregações como, por exemplo, dos jesuítas e dos oratorianos, trouxe em seu bojo a formulação de um conjunto de técnicas organizadas em torno de estratégias de ensino, além de um sistema normativo de atitudes e competências desejadas àqueles que se dedicassem ao desempenho dessa função.

Nos cursos de formação de professores, algumas disciplinas se dedicam ao ensino de metodologias. Ao analisar processos formativos direcionados aos professores destaca o caráter prescritivo e salvacionista neles implicado, nos quais novas propostas metodológicas são apresentadas, em tom de convencimento e com o suposto de trazerem a solução para os problemas relacionados ao ensino.

Além disso, essas técnicas ou modos de ensinar compõem a cultura escolar. Verifica-se que a cultura escolar consagra modos específicos de lidar com a vida escolar e as situações de ensino. Aprende-se a ser professor 


\section{Sérgio Junqueira}

Edile Maria Fracaro Rodrigues

em parte pela adoção de comportamentos relacionados à conduta do bom professor.

Diferentes autores, ao analisarem aspectos da prática educativa realizada pelos professores, apontam elementos para a compreensão das aprendizagens por eles efetuadas no exercício de sua função. A prática educativa se apoia mais em saberes da experiência, oriundos da cultura escolar, que em conhecimento advindo dos momentos de formação. Portanto, analisa a aprendizagem realizada pela socialização dos professores no ambiente escolar, em que os docentes aprendem a ensinar ao interiorizar normas, valores e condutas relacionados ao exercício da função, por meio do contato estabelecido com os colegas e com a instituição (CARDOSO, DEL PINO, DORNELES, 2012, pp. 2-3).

Assim como a formação dos professores diz respeito aos conteúdos das diferentes disciplinas ensinadas na escola (história, geografia, matemática, entre outras), e que não guardam relação direta com o conhecimento científico, mas são elaborados para serem ensinados. Além disso, convém destacar que a elaboração dos conteúdos escolares pressupõe uma seleção, em relação ao legado cultural acumulado pela humanidade.

Dessa forma, o conhecimento escolar diz respeito a conteúdos selecionados e que, a fim de possibilitar sua transmissão, são elaborados didaticamente e hierarquizados. Ao pôr em discussão a seleção realizada pela escola, em relação ao que nela é transmitido, destacam o fato de essa instituição operar um duplo arbitrário, uma vez que inculca arbitrário cultural cujo conteúdo foi arbitrariamente selecionado.

Para os autores, a seleção e a elaboração do conhecimento escolar diz respeito às necessidades sociais, ou seja, esse conhecimento é produzido na e para a escola, mas não é autônomo e relaciona-se a determinantes mais amplos. O sistema de ensino possui, no entanto, autonomia relativa, o que garante sua especificidade, o que se relaciona à forma escolar de transmissão. Os professores têm por tarefa transmitir o conhecimento escolar. Em sua prática, e em decorrência de questões relacionadas à função que exercem e aos determinantes objetivos de sua realização, estabelecem relação com o conhecimento escolar, por meio de livros didáticos e apostilas, sendo que, muitas vezes, nem mesmo com esse conhecimento possuem familiaridade.

Conforme destacado, em sua formação os professores têm contato com aspectos do conhecimento científico produzido em educação, que é parcial, pois é previamente filtrado e adaptado para utilização prática na 
sala de aula. Além disso, há saberes práticos a serem aprendidos, e sobre os quais, sem a possibilidade de compreensão mais ampliada em relação aos fins da educação e seus determinantes sociais, não estabelecem mediação. Entram também em contato com o conhecimento das disciplinas escolares, em relação às quais, em decorrência de deficiências em sua formação, têm dificuldade em se apropriar.

O trabalho do professor efetiva-se na sala de aula, no contato com os alunos, a quem direcionam o seu fazer, envolvendo uma série de tarefas anteriores e posteriores a esse contato, como orientar os estudos, ajudar os alunos, regular relações, preparo de materiais, seleção de atividades, organização do espaço.

Para tanto, o professor mobiliza saberes adquiridos pela experiência, por processos de formação e com o contato com os colegas. O professor toma decisões em função de julgamentos profissionais que não se limitam a fatos, baseando-se em valores morais, normas sociais, tradições escolares e experiência vivida.

Assim, cabe questionar em que condições o professor estabelece mediações com esse conhecimento que adquire com a experiência de trabalho, ou seja, o professor é capaz de refletir sobre essa experiência compartilhada nos momentos de socialização profissional, a fim de dela se apropriar de forma crítica, ou apenas reproduz tradições relacionadas à cultura escolar e seus modos consagrados de atuação? (FOSSATTI, SARMENTO, GUTS, 2012, pp. 72-74)

No que diz respeito às relações estabelecidas pelos professores com o universo do conhecimento, em decorrência do exercício docente, é importante ressaltar que, seja com relação à formação inicial ou continuada, seja em decorrência de aspectos do exercício mesmo da função, à docência nas primeiras séries da escolarização em escolas públicas, não exige e não proporciona às professoras a apropriação de conhecimentos científicos, relacionados à área da educação, e nem de conhecimentos relacionados às disciplinas escolares (CARDOSO, DEL PINO, DORNELES, 2012, pp. 10-11).

Os professores se apropriam mais de conhecimentos práticos, relacionados ao exercício da função, aprendidos especialmente no contato com os colegas. Dessa forma, os professores aprendem boa parte dos saberes, que utilizam no desempenho da docência, no contato com seus colegas e com aspectos da cultura escolar. Isso ocorre em situação em que não se exige dos professores, seja nos momentos de formação inicial, seja nos momentos 


\section{Sérgio Junqueira}

Edile Maria Fracaro Rodrigues

de formação continuada, maior profundidade, no que diz respeito a aportes teóricos, que permitam estabelecer reflexões sobre a prática, e na qual em geral se veem imersos, sem a possibilidade do estabelecimento de mediações.

Além disso, cabe destacar que, ao se considerar o campo educacional, em que a posse de conhecimentos legítimos é fator de distinção, verifica-se que a posição ocupada pelos professores do primeiro segmento do ensino fundamental é desprestigiada. O que demonstra a relação precária a eles imposta, exigida e propiciada, em decorrência do exercício dessa função. Ou seja, relação utilitária e permeada por sua aplicação prática, em que a apropriação de conhecimentos teóricos, relacionados à educação ou mesmo às áreas do conhecimento científico, não fazem parte de seu universo de possibilidades.

De fato, o saber fazer docente tem como pressuposto que o professor atue em determinado espaço social, é orientado por fatores normativos. Portanto, produzidos externamente ao ambiente escolar, como também por fatores internos, onde predomina a interação e reflexão desses com os demais atores do ambiente educativo.

Dessa maneira, o saber docente do profissional, está relacionado às necessidades de ordem cultural, pedagógica e social ao ambiente em que atua. Essa situação reporta, portanto, às diferentes dimensões da ação docente, e às quais podem estar vinculadas: a construção de instrumentos; elaboração e execução de tarefas; as escolhas metodológicas; a gestão do conteúdo e da sala de aula e ao planejamento. Além da dimensão epistemológica, como as concepções reducionistas sobre ensino, aprendizagem e docência. Essas dimensões estruturam o trabalho pedagógico, a prática, o saber agir e o saber fazer e estão relacionados a um objetivo e ação.

Nesse sentido, o saber fazer docente é compreendido como um saber instrumental do fazer docente, o qual é elaborado a partir das diferentes relações e dimensões, que se estabelecem no âmbito escolar, além de estar relacionado aos meios para alcançar o objetivo proposto. Este saber também tem como base o saber integrador, o qual é proveniente das pesquisas realizadas na área de ensino, dos conteúdos escolares, e que apresenta como premissa a identificação dos obstáculos referentes ao desenvolvimento da prática docente.

Assim, um saber integrador, busca entender como se ensina e se aprende um determinado conteúdo e em detectar os principais problemas enfrentados na formação de professores. 
Um dos principais obstáculos que envolvem a formação dos professores refere-se às ideias apresentadas sobre o ensino e a aprendizagem, em que a compreensão dos futuros professores é o resultado de uma postura baseada no senso comum e adquirido de forma não reflexiva. Nesse sentido, os professores têm ideias, atitudes e comportamentos sobre o ensino, formados durante o período em que foram alunos, adquiridos de formação não reflexiva, como algo natural, óbvio, escapando, desta forma, à crítica, e se transformando em um verdadeiro obstáculo para uma mudança didática.

Desta forma, a prática pedagógica tem como preocupação o conjunto de sujeitos para quem se ensina, além de envolver ações intencionadas e sistemáticas, ligadas a eles, bem como ao local. Desse modo, pode-se verificar que a atividade de ensino relaciona sujeitos distintos, com objetivos diferentes, os quais necessitam interagir para que as suas ações e objetivos possam se concretizar. Essa interação pode ser permeada por ações de resistência e de conflito dos envolvidos, já que os objetivos podem ser diferentes, bem como as concepções apresentadas pelos participantes. Dessa maneira, existem diferentes possibilidades de interagir, podem ser elas na esfera instrumental, estratégica, no âmbito do entendimento ou ainda uma interação comunicativa.

Verifica-se que os objetivos e princípios comuns às reformas da formação de professores visa conceber o ensino como uma atividade profissional, que se apoia num sólido repertório de conhecimentos; visa também considerar os professores como práticos reflexivos; ver ainda a prática profissional como um lugar de formação e de produção de saberes práticos; e, por último, instaurar normas de acesso à profissão e estabelecer ligação entre as instituições universitárias de formação e as escolas da Educação Básica.

Os saberes referentes ao conteúdo, à experiência e à cultura são essenciais no exercício da atividade docente, mas tomá-los como exclusivos é mais uma vez contribuir para manter o ensino na ignorância e reforçar a perpetuação de um ofício sem saberes. O segundo obstáculo diz respeito aos saberes sem ofício, que têm sua origem nas Ciências da Educação, ou seja, são os conhecimentos produzidos nos centros acadêmicos (PILATTI, 2015,pp. 42.292-42.294).

Muitos desses conhecimentos foram produzidos sem considerar as condições concretas do exercício do magistério. São os saberes que não se dirigiram ao professor real, cuja atuação se dá numa sala de aula concreta, e onde estão presentes muitas variáveis que interferem no processo de ensino e 
Edile Maria Fracaro Rodrigues

exigem tomadas de decisão, ou seja, buscou-se formalizar o ensino reduzindo de tal modo a sua complexidade que ele não mais encontra correspondente na realidade.

O desafio da profissionalização docente é evitar esses dois erros: ofício sem saberes e saberes sem ofício. Sendo que a formação inicial visa habituar os alunos, futuros professores, à prática profissional dos professores de profissão e, fazer deles, práticos reflexivos.

Portanto, uma das inovações do trabalho é compreender o saber do professor como saberes, que têm como objeto de trabalho o ser humano, e advém de várias instâncias, ou seja: da família, da escola que o formou, da cultura pessoal, da universidade. Provêm ainda, dos pares, dos cursos da formação continuada. É também plural, heterogêneo e temporal, pois se constrói durante a vida e o decurso da carreira, portanto, é personalizado, situado.

Essa concepção da amplitude de saberes que forma o saber do professor é fundamental para entender a atuação de cada um no processo de trabalho coletivo desenvolvido pela escola. Cada professor insere sua individualidade na construção do projeto pedagógico, o que traz a diversidade de olhares, contribuindo para a ampliação das possibilidades e construção de outros novos saberes.

Refletindo sobre o processo de formação de professores, cada professor insere sua individualidade na construção do projeto pedagógico, o que traz a diversidade de olhares, contribuindo assim para a ampliação das possibilidades e construção de outros novos saberes, que deve levar em conta o conhecimento do trabalho dos professores, seus saberes cotidianos.

Tal postura desconstrói a ideia tradicional de que os professores são apenas transmissores de saberes, produzidos por outros grupos. Efetivamente o conhecimento é uma apropriação cognitiva de um determinado objeto externo: o sujeito obtém uma imagem cognitiva interna de uma realidade externa. O saber implica uma relação entre o sujeito, o conhecimento e seu contexto, ou seja, uma interação sujeito-mundo. Construir conhecimentos seria objetivar informações, dados, conceitos. Construir saberes seria movimentar esses conhecimentos no contexto de ação, reinventando-os, recriando-os e traduzindo-os, de acordo com as circunstâncias da situação.

Desta forma, o saber escolar é uma categoria de análise do conhecimento escolar e surgiu no contexto dos estudos que investigam a relação entre escola e cultura, bem como o papel desempenhado pela escola na produção da memória coletiva, de identidades sociais, e na reprodução 
das relações de poder, através de seus mecanismos e estratégias de seleção cultural escolar.

Dado o processo de construção ativa do saber, que requer o trabalho, se pode supor que a prática docente não é reprodução passiva da formação profissional ou das normas oficiais. A diversidade de práticas, concretas nas escolas, a heterogeneidade de soluções aos problemas da instituição e a variedade de formas de ensinar, demonstram que o processo de construção do saber do magistério é seletivo e inclusive inovador.

A formação de professores não é uma abstração incondicional. É preciso ter claro os objetivos a serem conquistados com essa formação, embora esse processo seja sempre contextualizado socialmente.

3. A construção da identidade do Ensino Religioso Escolar no Brasil

A visão cristão-judaica é um dos fatores de uma certa marmorificação dos conceitos de leitura e compreensão das culturas. Existe uma grande dificuldade de entender o oriente quando utilizamos as referências eurocêntricas no entendimento de um espaço como são as culturas orientais, pois a formação semita profundamente marcada pela perspectiva cristã nos prende a uma concepção de mundo que não é a mesma do oriental.

A colonização da América Latina, por exemplo, foi baseada na tecnologia da arma. Uma proposta de superioridade sustentada pelo poder da força, que persiste mesmo no início do século XXI. Percebe-se essa realidade pelas pesquisas que estão voltadas para manutenção de poder de grupos aliados a indústria das armas e da morte. A imprensa de Gutenberg tinha como finalidade a impressão de textos sagrados e o papel moeda, que estava a serviço de uma ação na comunidade. Já entre os orientais, a imprensa na realidade permitiu outros produtos e propostas (ORO; URETA, 2007, pp. 282-283).

Ao refletir sobre a religião como organizadora do cotidiano social, encontra-se como elemento fundante toda a contribuição dos judeus. Estes, envolvidos com o comércio, permitiram o encontro de culturas diversas, favorecendo assim a troca de conhecimentos e estabelecendo uma forma de olhar o cotidiano produzindo uma síntese de vida. Por exemplo, a ideia de apocalipse da religião cristã é algo que já era refletido por outros povos, na história da filosofia no ocidente e também foi assumida por autores como Thomas Morus ao criar o termo UTOPIA como um lugar melhor, no fundo é o apocalipse. Isto é, nos decepcionamos com o mundo real e para tal criamos um mundo melhor para manter os sonhos, esta é uma das funções das religiões. 


\section{Sérgio Junqueira}

Edile Maria Fracaro Rodrigues

Portanto, não é possível entender a religião sem compreender a sua estrutura. Como pressuposto ela está localizada dentro de um espaço chamada cultura, que é tudo aquilo produzido pelo ser humano. Ou seja, a religião é algo construído pelas comunidades, existe em contextos históricos, por este motivo as tradições religiosas são extremamente dinâmicas.

Para refletir sobre a tradição religiosa e compreendê-la é necessário desconstruir os modelos que justificam a superioridade entre os grupos religiosos. Nesse processo é fundamental compreender o movimento histórico no ocidente e oriente, depois entender os paradigmas que sustentam as culturas, ou os movimentos de elaboração do conhecimento dentro das culturas, por exemplo um modelo de história oriental e a ocidental. A história é linear, tem começo, meio e fim, e está intimamente relacionada com a ideia de deus ocidental. Motivo pelo qual se encontram livros onde o Budismo é apresentado como um ateísmo religioso, por não se compreender a concepção de deus oriental que é elíptica, espiral, formada por ciclos. O deus ocidental é o criador, visão linear, no oriente ele é o organizador, o transcendente que sempre esteve nesta criação. O Kaos é uma dinâmica já criada em que o deus organiza, enquanto no ocidente o caos é uma bagunça em que para pôr ordem é necessário até mesmo excluir.

Por esse motivo, pode-se dizer que existem teologias, esta é uma área do conhecimento humano, que possui como função atualizar, captar o tempo interior, a essência do sagrado que vive, fundamentada dentro dos textos, expressos nos ritos com seus diferentes símbolos. Por isto é importante compreender que o texto não é apenas o sistematizado por grafias, mas as diferentes formas que permitem a leitura do contexto das comunidades. Portanto, retornamos a questão da cultura e a efetivação por meio das tradições.

Ressalta-se a tradição, que é um componente da cultura e a base do estudo teológico. As comunidades possuem PALAVRA - TRADIÇÃO - MAGISTÉRIO, o texto sagrado que faz parte da tradição são fatos e acontecimentos que marcam a vida do grupo, que sustentam as escolhas das comunidades. No caso dos cristãos dois fatos assumiram Significatividade a última ceia e a crucifixão, celebrada e refletida pelos mestres assumem o papel de magistério da comunidade.

No Brasil, a escola organizou-se a partir de especialização de "matérias" que, compartimentadamente, eram ministradas aos estudantes. No entanto, muitas disciplinas eram estreitamente imbricadas, a ponto de o mesmo professor encarregar-se de diversas tarefas escolares, com finalidade educativa 
imposta segundo a especialidade do mesmo (RODRIGUES; JUNQUEIRA, 2009, pp. 21-22).

Com o fenômeno da urbanização acelerada, decorrente do desenvolvimento do capitalismo industrial, criou-se uma forte expectativa com relação à educação brasileira. A complexidade maior do trabalho exigia melhor qualificação da mão de obra. Mas é somente no século XX que estes esforços se concretizam. Com a intervenção cada vez maior do Estado brasileiro consolidase a escola elementar universal, leiga, gratuita e obrigatória. Ao longo desse processo ocorre a discussão sobre a compreensão do que são as disciplinas escolares como uma maneira de organizar e delimitar um território de trabalho, de concentrar a pesquisa e as experiências dentro de uma determinada visão. Daí que cada disciplina oferece uma imagem particular da realidade, isto é, daquela parte que entra no ângulo de seu objetivo.

Disciplinas, ou componentes curriculares, são saberes elaborados pela humanidade e referências de mundo no qual o estudante está inserido. Estas apresentam especificidades e saberes próprios, construídos e sistematizados com elementos de domínio de uma linguagem própria; compreensão do fenômeno específico, que contribui para o enfrentamento de situações, a partir da construção de argumentos; e a elaboração de propostas que organiza o ensino no interior da escola.

Enfim, as disciplinas escolares têm origem nas ciências, no desenvolvimento das linguagens, no mundo do trabalho, na cultura e na tecnologia, na produção artística, nas atividades desportivas e corporais, na área da saúde. Ainda incorporam saberes como os que advêm das formas diversas de exercício da cidadania, dos movimentos sociais, da cultura escolar, da experiência docente, do cotidiano e dos alunos. E os seus devidos conteúdos constituídos se articulam com as áreas de conhecimento, que favorecem a comunicação entre os conhecimentos e saberes das diferentes disciplinas, mas permitem que os referenciais próprios de cada componente curricular sejam preservados, a saber: Linguagens, Matemática, Ciências da Natureza e Ciências Humanas (JUNQUEIRA. 2015, pp. 17-19).

Progressivamente os sistemas escolares brasileiros foram estabelecendo a ciência de referência para sustentar teoricamente o Ensino Religioso Escolar como componente curricular. Fundamentalmente referenciou-se em duas perspectivas: uma no modelo confessional - a proposta original desde a sistematização desta disciplina, e o não confessional que está sendo elaborado a partir do reconhecimento da pluralidade religiosa da sociedade. 


\section{Sérgio Junqueira}

Edile Maria Fracaro Rodrigues

Logo, o fenômeno da transposição didática põe em evidência o fato de que a disciplina escolar não é o conhecimento científico, mas uma parte dele e, além disso, torna-se modificada. Por outro lado, é mais do que o conhecimento em si, porque abarca também os procedimentos para o ensinar. Fazer a transposição didática implica em algumas competências, ou seja, é preciso estar atento para desenvolver o aprendizado, e isto deverá estar contemplado no plano de educação continuada da escola, da região ou do sistema de ensino. Ainda, é preciso saber fazer recortes na área de uma especialidade, de acordo com um julgamento sobre relevância, pertinência e significância.

E, para além disso, é necessário ainda, para o desenvolvimento das competências escolhidas, garantir a inserção do aluno no mundo moderno; saber selecionar os aspectos relevantes do conhecimento; dominar o conhecimento em questão, de modo articulado, incluindo o modo característico e específico pelo qual o conhecimento é construído. E, por último, saber relacionar o conhecimento em questão com os de outras áreas; saber como contextualizar o conhecimento trabalhado; e dominar estratégias de ensino eficazes para organizar situações de aprendizagem que, efetivamente, promovam no aluno as competências que se quer desenvolver (SANTOS, 2018, pp. 46-48).

Com essa perspectiva, o Ensino Religioso Escolar não confessional propõe o respeito à liberdade e o apreço à tolerância religiosa diante do pluralismo de ideias e concepções pedagógicas. O Ensino Religioso Escolar no Brasil visa divulgar a cultura, a partir do estudo dos conhecimentos religiosos, assim como o reconhecimento e o respeito às alteridades, como um espaço de aprendizagens, experiências pedagógicas, intercâmbios e diálogos. Busca ainda o acolhimento das identidades culturais religiosas, com uma perspectiva intercultural de direitos humanos e a cultura da paz, para proporcionar a partir das manifestações religiosas percebidas na realidade dos educando, a aprendizagem dos conhecimentos religiosos, culturais e estéticos, e contribuir com o diálogo entre as perspectivas religiosas e seculares exercitando a liberdade de expressões (FILORAMO; PAJER, 2011, pp. 22-123).

O conhecimento religioso visa não apenas o saber pelo conhecer, mas a compreensão da realidade e a intervenção social a partir da construção de informações. E no caso específico do Ensino Religioso Escolar, formar cidadãos em uma concepção de respeito pela diversidade religiosa, em acordo à laicidade do Estado. 
Nesse sentido, este componente curricular é orientado para que os estudantes dominem as diferentes linguagens, compreendam os fenômenos, sejam físicos ou sociais, construam argumentações para elaborar propostas e enfrentem as diversas situações de suas vidas. (RODRIGUES; JUNQUEIRA, 2009, pp. 155-156).

A proposta do Ensino Religioso Escolar é a de promover uma cultura $\mathrm{d}$ a reciprocidade, como ideal regulativo da convivência que se articula em três momentos. O primeiro: a estima de si. O segundo, o cuidado pelo outro. E o terceiro a aspiração de viver em instituições justas.

Essa visão da reciprocidade exige uma redefinição, tanto do conceito de comunidade como do de cidadania. Comunidade deriva do latim communitas, que se fundamenta na palavra múnus, que significa tarefa, obrigação, dever, mas também dom. Se alguém faz parte de uma comunidade, portanto, é porque no interior dela deve-se assumir uma responsabilidade. Compreendendo que esta comunidade possa ser a escola, ela é um espaço de construção coletiva de conhecimentos. E a proposta pedagógica visa possibilitar a articulação de conteúdos de ensino e de aprendizagem. E, ainda, com vivências e indagações do professor e dos alunos sobre a realidade em que vivem. Perceber que uma das tarefas da escola é fornecer instrumentos de leitura da realidade e criar as condições para melhorar a convivência entre as pessoas pelo conhecimento (GENRE; PAJER, 2005, pp. 18-19). Logo, isto é construir pressupostos para o diálogo.

\section{Considerações}

A compreensão do Ensino Religioso Escolar a partir da organização da educação e da relação da religião na sociedade trouxe novos desafios e olhares para a complexidade desse componente curricular. considerando os aspectos pedagógicos e legais brasileiros.

Retomando a questão norteadora do presente artigo, buscou-se estabelecer as referências sobre a identidade de Ensino Religioso Escolar e sua respectiva formação docente, como início de diálogo no cenário latino-americano.

As discussões e debates sobre Ensino Religioso Escolar no Brasil colaboram para a construção da identidade do componente curricular bem como sua respectiva formação docente. Essa construção considera o contexto religioso e educacional de nosso país desde o século XVI. E nos dias atuais 


\section{Sérgio Junqueira}

Edile Maria Fracaro Rodrigues

com a valorização da diversidade cultural e religiosa presente na sociedade brasileira, contribuem para a reflexão de sua função no ambiente escolar.

A efetividade do Ensino Religioso Escolar está vinculada à qualificação da formação do professor. Tal efetividade só se concretiza no processo de ensino e aprendizagem direcionado para uma dinâmica envolvendo a cognição e a relação entre sujeitos. Esses saberes se constituem ao longo do processo de escolarização no curso de formação e na prática profissional, e são decorrentes do enfrentamento dos problemas da prática. Isso envolve ouvir o relato dos professores com o conhecimento a ser ensinado, ou seja, os saberes da experiência, os saberes pedagógicos e específicos e os saberes das lutas cotidianas.

Quando o Ensino Religioso é compreendido como divulgador de uma concepção religiosa a formação do professor e os textos didáticos podem ser explicitamente doutrinários. Já uma perspectiva antropológica a partir de valores identifica uma formação de compreensão da religiosidade presente no ser humano e na sua história. Dessa forma, para compreender os pressupostos para a formação do professor de Ensino Religioso é necessário dar uma identidade de disciplina.

Não há a intenção de estabelecer a relação direta e determinista entre o processo intencional de formação e a sua concretude. Muitos fatores são intervenientes e assumem a condição de relatividade no processo que é sempre único. Entretanto, a explicitação de objetivos sinaliza a opção política e epistemológica adotada, que deve inspirar a formação. A consequência deste percurso da formação é verificar que os países como a Colômbia em uma perspectiva teológica (VIDES, 2016, pp. 90-91) em cursos denominado de Ciências Religiosa prepara o docente como um evangelizador. Em contrapartida, no projeto da disciplina para o Brasil a perspectiva é de uma leitura da cultura da religião em projetos de cursos de Ciência da Religião.

Embora este Projeto esteja em andamento, a teoria dos saberes docentes do educador canadense permite perceber, em muitos aspectos, como são essenciais os fundamentos da formação de professores de Ensino Religioso, seus impactos no trabalho de docente e sua relação com as concepções deste componente curricular. A proposta é que após a sistematização teórica, será necessário o confronto com professores em formação para consolidar esta relação com as concepções da disciplina no cenário brasileiro e latino-americano, visando verificar esta relação para a consolidação desta área de estudo nos diferentes sistemas de ensino. 
A formação de professores, como processo contínuo, no exercício da docência não trata apenas em saber fazer, mas saber o que fazer, como fazer, por que fazer e a serviço de que interesse se coloca o fazer dos educadores (o que se faz como educador). E torna-se responsabilidade da escola e do professor desenvolver seu projeto de formação, num processo de reflexão e de intervenção contínua, uma vez que ele é o agente de sua prática pedagógica. Essas dicotomias ainda serão verificadas a partir dos sistemas de ensino que lidam com o Ensino Religioso.

O conhecimento profissional do docente é concebido como um estado de contínua construção e aperfeiçoamento. Isso se dá pelo desenvolvimento acelerado do conhecimento social; pelas bases do conhecimento escolar; bem como pelas estruturas materiais e institucionais da sociedade. Os mesmos tornam-se reflexos significativos nas formas de pensar, agir e sentir das novas gerações de alunos. Nesse sentido, o trabalho docente entra como práxis, onde a teoria/prática se caracteriza pela ação/reflexão/ação. Ou seja, o professor aprende, compreende e transforma a situação de ensino e ao mesmo tempo é transformado por ela.

Portantoo, organizar a formação deste profissional, para o Ensino Religioso Escolar no Brasil, pressupõe a compreensão de que o saber religioso não assume a proposta da fé para orientar atuação em uma comunidade, mas a inferência que a religião assume na sociedade com todas as suas consequências. Ou seja, é levar a compreender para respeitar.

O Ensino Religioso Escolar no Brasil vem se estruturando como um dos marcos de leitura e interpretação da realidade, essenciais a participação do cidadão na sociedade de forma autônoma. Assim, ele assume uma perspectiva a partir da escola, como orientação de um processo articulador no dia a dia da sala de aula, desafiando o (re) olhar sobre o processo de ensino-aprendizagem.

\section{Referencias}

BLOCK, O.; RAUSCH, R (2015). Saberes docentes: dialogando com Tardif, Pimenta e Freire. UNOPAR: Ciências Humanas, Educação. 3(15), pp. 249-254.

BRASIL. Lei de diretrizes e bases da educação nacional LEI 9394/96. Brasília: MEC, 1996.

CARDOSO, A.; DEL PINO, M.; DORNELES, C (2012). Os saberes profissionais dos professores na perspectiva de Tardif e Gauhier: contribuições para o campo da pesquisa sobre os saberes docentes. In: IX ANPED. Curitiba: PUCPR, pp. 1-12. 


\section{Sérgio Junqueira}

Edile Maria Fracaro Rodrigues

FILORAMO, G.; PAJER, F (2011). Di che Dio sei? Tante religione um solo mondo. Torino: SEI.

FONTANA, M (2015). Política e formação continuada de professores para a pesquisa na e com a escola do campo. In. Revista Brasileira de Pesquisa sobre formação docente. 13(07), pp. 99-114.

FOSSATTI, P.; SARMENTO, D.; GUTHS, H (2012). Saberes docentes e à docência na sociedade contemporânea: olhares diferentes. In: Comunicações. 1(19), pp. 71-85.

GENRE, E.; PAJER, F (2005). L'Unione Europea e la sfida delle religione. Verso uma nuova presenza della religione nella scuola. Torino: Claudiana.

JUNQUEIRA, S (2015). Uma ciência como referência: uma conquista para o Ensino Religioso. In. Rever: revista de Estudos da Religião. 2(15), pp10-25.

; GABRIEL JÚNIOR, R. F.; KLUCK, C. R.; RODRIGUES, E.M.F. Socialização do saber e produção científica do ensino religioso [recurso eletrônico]. Porto Alegre, RS: Editora Fi, 2017

LEME, M (2018). Hacia una educación religiosa generadora de convivialidad y respeto en las diversidades. In, Revista Pedagógica 20(44), 27-41.

ORO, A.; URETA, M. (2007) Religião e política na América Latina: uma análise da legislação dos países. In: Horizontes Antropológicos 27(13), pp. 281-310.

PILATTI, P. Saberes docentes expressos na prática dos professores dos anos iniciais do ensino fundamental. In. Curitiba: XII Educere, 2015, pp. 42.290-42.299.

PINTO Paulo Mendes. O ensino da Religião na Escola Laica — uma leitura do "Relatório Debray”. ULHT (Universidade Lusófona de Humanidades e Tecnologias). Revista Lusófona de Ciência das Religiões - Ano XI, 2012 / n. 16/17 - 11-30.

RODRIGUES, E.; JUNQUEIRA (2009), S. Fundamentando pedagogicamente o Ensino Religioso. Curitiba: IBPEX.

SANTOS, R (2018). Ciência da Religião e transposição didática: compreensão e impacto no ensino religioso. In: PLURA, Revista de Estudos da Religião. 1(09), pp. 30-55.

SERRES, G. Formação docente (2011). In: ZANTEN, A (Org.). Dicionário de educação. Petrópolis: Vozes, pp. 425-429.

SILVA, F (2006). Cultura escolar: quadro conceitual e possibilidades de pesquisa. In. Educar, 1(28), pp. 201-216.

TARDIF, M. Saberes docentes e formação profissional. Petrópolis: Vozes. 2002.

; LESSARD, C. O Trabalho docente: Elementos para uma teoria da docência como profissão de interações humanas. Petrópolis: Vozes. 2005.

VIDES, D (2016). La Educación Religiosa Escolar como espacio de formación política. Marco antropopedagógico desde la experiencia de docentes de Instituciones Educativas Distritales de Bogotá. Bogotá: Universidad de la Salle.

Submetido em: 28-8-2019

Aceito em: 13-4-2020 